\title{
In vivo wound Healing Activity of Ointment based Formulation for Prunus amygdalus (Batsch.) on Rats
}

\author{
Diksha Singh ${ }^{1}$, Kashmira J Gohil', Vikash Sharma ${ }^{1, *}$, Shiv Shankar Shukla² \\ ${ }^{1}$ Department of Pharmacology, Anand College of Pharmacy, Agra, Uttar Pradesh, INDIA. \\ ${ }^{2}$ Department of Pharmaceutical Analysis, Columbia Institute of Pharmacy, Raipur, Chhattisgarh, INDIA.
}

\begin{abstract}
Objectives: The present study is to investigate the wound healing activity of F1-PAO and F2-PAE ointment formulations based on Prunus amygdalus oil and extract respectively. Materials and Methods: The ethanolic and n- hexane extract of Prunus amygdalus (Batsch.) Seed (Nut) was done and incorporate to make F1-PAO and F2-PAE ointments formulations. Above formulations were investigated for their wound repairing potential by excision and incision model in Albino wistar Rats. Animals were divided in five groups, each containing 6 animals. Group I (control) no treatment, Group II (Negative group) treated with simple ointment base, Group III was standard, treated with marketed formulation (Betadine). Group IV (F1-PAO) and Group V (F2-PAE) in excision and Incision model treated with ointments prepare from Prunus amygdalus (Batsch.) extract and oil. The wound healing process was examined with the naked eye until the wounds were fully healed. In excision model, wound contraction rate while, in incision model tensile strength (skin breaking strength) was observed and evaluated. The data obtained was statistically verified by using one-way ANOVA followed by Dennett's test. Results and Discussion: Both the formulations significantly reduced the wound area and enhanced percentage of wound closure with compared to Positive control group, but healing process in F2-PAE was found to better than F1-PAO. Recent studies already suggested about the phytoconstituents present in extract formulation and oil-based formulation. Alkaloid and tannins were supposed to be present F2-PAE and responsible for better effect than F1-PAO. Conclusion: The investigation showed that both ointment formulation i.e., F1-PAO and F2-PAE treated groups have significant wound healing activitiy but F2-PAE was found to be more effective than F1-PAO.

Key words: Prunus amygdalus (Batsch.), Almond, Wound healing, Excision, Incision.
\end{abstract}

\section{INTRODUCTION}

A wound is a breaking or opening in the skin caused by a disruption of normal anatomical structure. ${ }^{1}$ It also defined as "a disruption of a tissue's cellular and anatomic continuity, with or without microbial infection, which occurs as a result of an accident or a cut with sharp edged objects". ${ }^{2}$ High level of morbidity is associated with a lack of blood, pain, edema, inflammation and loss of function. ${ }^{3}$

Wound infections constitute one of the most common acquired hospital infections, an important cause of injury and $70-80 \%$ death. ${ }^{4}$ Various plants and their products are being used in the field of folk medicine for the treatment of the wound and plants such as Ginseng, Sunflower, Brahmi, etc. ${ }^{3}$ Medicinal plants have been used as an alternate source of medicine in almost all cultures. Herbal medicines, according to WHO, play an important role in providing the healthcare needs of approximately $80 \%$ of the world's population, especially for millions of people in rural areas of developing countries's. ${ }^{5}$

PA (Prunus amygdalus Batsch.) belonging to the family Rosaceae is common is a common nut found in Punjab, Kashmir, and Himachal Pradesh and commonly known as Almond (Badam). ${ }^{6,7}$ Badam seed carries flavanol,
Submission Date: 05-05-2021; Revision Date: 17-08-2021; Accepted Date: 09-11-2021.

DOI: 10.5530/ijper.56.1.21 Correspondence:

Mr. Vikash Sharma Department of Pharmacology, Anand College of Pharmacy, Agra-282007, Uttar Pradesh, INDIA.

E-mail: vikassharma10588@ gmail.com

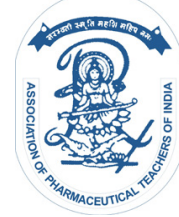

www.ijper.org 
glycosides involving kaempferol glucoside, rutinoside, kaempferol, isorhamnetin, and isorhamnetin glucoside. Also, Badam also comprises phenolic constituents like phydroxybenzoic acid, $30 \alpha$ lrhmnopyranosyl, $30 \beta$ Dgalactopyranoside, catechin, 3'Omethylquercetin, protocatechuic acid, and vanillic acid. The nut Extract and oil are used traditionally for its anti-oxidant activity, ${ }^{8,9}$ antifungal activity, Anti-depressant activity, ${ }^{10}$ Anti-diabetic activity, ${ }^{11}$ etc. The nut extract never been studied for wound healing activity. Almond seeds are nutritious oil seeds that are rich in fiber, calcium, Vitamin E and protein. Almond oil is highly nutritious with high phytochemical content. Almonds are high in Vitamin E, magnesium, copper, phosphorus, riboflavin, monounsaturated fatty acids, protein, folic acid, alpha tocopherol, zinc, manganese and Vitamins $\mathrm{A}, \mathrm{B}_{1}, \mathrm{~B}_{2}$, and $\mathrm{B}_{6} \cdot{ }^{12,13}$

The presnt study is aimed to investigate the wound healing activity of F1-PAO (Oil containing ointment formulation) and F2-PAE (Extract containing ointment) formulations based on Prunus amygdalus.

\section{MATERIALS AND METHODS}

\section{Collection and authentication of seed (Nut)}

The seeds (Nuts) were collected from the local market of Agra, Uttar Pradesh, India in December 2020. Herbarium of the plant material was authenticated at the Raja Balwant Singh College, Agra, U.P, and was authenticated by Dr. K.P. Singh, Botanist.

\section{Drugs and Chemicals}

$5 \% \mathrm{w} / \mathrm{w}$ Povidone iodine ointment (Betadine) was used as standard. Woolfat, Cetostearyl alcohol, hard paraffin, and Yellow soft paraffin was used to prepare the ointment base and procured from Anand College of pharmacy, Agra. All the chemical used in the study were of analytical grade.

\section{Preparation of Seed extract}

The Almond seeds were dried and coarsely powdered for extraction. Soxhlet apparatus was used for extraction. $500 \mathrm{~g}$ of powder was taken for $48 \mathrm{hr}$ with ethanol. The alcoholic extracts of the Almond seeds were dried in a rotary evaporator at $4^{\circ} \mathrm{C}$ to produce a semi-solid mass and stored in an airtight container below $10^{\circ} \mathrm{C}$ in the refrigerator. ${ }^{13}$ The extraction yield of almond nut is $12.2 \% \mathrm{w} / \mathrm{w}$ on dried weight and it was contained in desiccators for pharmacological investigation.

\section{Preparation of seed oil}

The dried powdered almond seeds were extracted in a soxhlet apparatus with $\mathrm{n}$-hexane, the oil was obtained on a rota vapor apparatus after evaporation of the solvent at $40^{\circ} \mathrm{C}$ under reduced pressure. ${ }^{14}$ The extraction yield of almond oil is $53.25 \%$. It stored in room temperature.

\section{Phytochemical investigation}

The extract of PA Seed was qualitatively examine for the present of phytoconsittuents like phenolic derivatives, saponins, tannins, flavonoids, triterpenoids, and alkaloid by proceed a standard procedure. These have been defined by typical color change used the standard procedure. $^{15,16}$

\section{Test for saponins}

Froth test: The extract was heated for 2 min with five mililitre of water; the solution was cooled and continusly shaken, then left for three minutes. The development of frothing results that saponins are present.

\section{Test for triterpenes}

Salkowski test: The extract was mixed with five $\mathrm{ml}$ of $\mathrm{CCL}_{4}$ and heated for $30 \mathrm{~min}$ at $8^{\circ} \mathrm{C}$. It was included and mixed well with a few drops of con. $\mathrm{H}_{2} \mathrm{SO}_{4}$. The red color appearance indicates the triterpenes are present.

\section{Test for Tannins}

Gelatin test: One $\mathrm{ml}$ of extract was added two $\mathrm{ml}$ of $\mathrm{NaCl}(2 \%)$ filtered, and mixed with five $\mathrm{ml}$ of $1 \%$ gelatin solution. In this solution tannins was present indicates precipitation.

Alkaline reagent test: The $\mathrm{NaOH}$ sol. with extract gave yellow to red precipitate in a short time.

\section{Test for Alkaloids}

Mayer's test- 5-6 drops of Potassium mercuric iodide solution was mixed to $1 \mathrm{ml}$ of the test sample and observed to obtain cream color.

Dragendroff's test- 5-6 drops of Potassium bismuth iodide solution was mixed to $1 \mathrm{ml}$ of the test sample and noticed for red to brown color. ${ }^{17,18}$

\section{Test for phenols}

Ferric Chloride test- sample was interacting with 5-6 drops of alcoholic $\mathrm{FeCl}_{3}$ liquid. Observation of brown look indicates Phenol.

\section{Test for flavonoids}

Alkaline reagent test- About $1 \mathrm{ml}$ sample was added with 4-5 drops of sodium hydroxide solution and dark yellow look was visible that vanish on adding of dilute $\mathrm{HCl}$.

\section{Test for Steroids}

Liebermann Burchard's test- Observing sample in $1 \mathrm{ml}$ quantity was interacting with $2-3 \mathrm{ml}$ of acetic anhydride which further heated and cooled. Add conc. 
$\mathrm{H}_{2} \mathrm{SO}_{4}$ slowly and noticed for a chocolatey circle at inter junction.

\section{Experimental animals}

Male Wistar rats weighing 150 to $180 \mathrm{~g}$ were used in the research work. The experimental procedures were approved by the IAEC of Anand College of pharmacy, Agra, U.P, India, priors to the conducted of the animal experiments, vide approval no. 1353/ac/10/CPCSEA, dated 30/01/2021. Animals were accommodated under constant conditions $\left(25 \pm 2^{\circ} \mathrm{C}\right.$, humidity $40-60 \%, 12 \mathrm{hr}$ light: $12 \mathrm{hr}$ dark cycle. The animals were serves with a diet of regular foodstuffs and water ad libitum during maintenance. The animals were anaesthetizing before and while the trial injuries were induced. Procedures were performed under sterile conditions by administering $25 \mathrm{mg} / \mathrm{kg} \mathrm{BW}$ (i.p) pentobarbitone sodium in a normal position.

\section{Preparation of ointments formulations}

The next step was to develop a preparation of ointment after extract and photochemical study. There are two ointment as follows: Formulation1- Prunus amygdalus Batsch. Oil (F1-PAO) and formulation 2- Prunus amygdalus Batsch. extract (F2-PAE).

The ointment was made from the base of the ointment. In the beginning it was prepared with precise scraping of hard paraffins on the water bath in the evaporating dish to measure the base of the ointment. After the hard paraffin was melted, the woolfat, Cetostearyl alcohol and yellow soft paraffin were added and mixed carefully to help melt homogenously, followed by the ointment base cooling. ${ }^{19}$

F1-PAO and F2-PAE were prepared by mixing the accurately weighted almond extract and almond oil with an antiseptic agent and soothing agent to the ointment base was prepared a smooth paste with the help of levigation method of two or three times its base wt, slowly adding more base until the homogeneous ointment is formed, eventually transferred into a sufficient ointment. ${ }^{18}$ The prepare both ointments was evaluated the various parameters like color, odor, spreadability study, Consistency, Solubility, Stability etc. ${ }^{19}$

\section{Grouping and drug treatment}

For in excision and incision model, the rats were divided into five groups (Contianing 6 animals each) as follows: Group 1: Control group, No treatment

Group 2: Negative Group, Treatment with simple ointment base

Group 3: Positive Group, Treatment with Standard drug (Betadine)
Group 4: F1-PAO, Excision model and incision models treated with formulation 1 ointment

Group 5: F2-PAE, Excision model and Incision model treated with formulation 2 ointment

Wound healing activity: Following two models were used for this study

(a) Excision model, (b) Incision model

\section{Excision wound healing model}

Pentobarbitone sodium ( $25 \mathrm{mg} / \mathrm{kg}$ b.w i.p.) was used to anaesthetize the rats. $30 \mathrm{~min}$ after the pentobarbitone sodium injection, a diameter of excision wound of circular area with the help of biopsy punch $(5 \mathrm{~mm}$ diameter) and two millimeter deepness was made on the razored backs of the rats. The injury day was measured on day 0 . The injuries were supervised, and the area of the injury was examined on $4^{\text {th }}, 8^{\text {th }}, 12^{\text {th }}$, and $16^{\text {th }}$ postwounding days, as well as the mean percent wound closure. $^{20}$

\section{Wound healing rate}

Percentage of Wound Closure -

$$
\frac{\text { Wound area on day } 0-\text { Wound area on day } \mathrm{n}}{\text { Wound area on day } 0} \times 100
$$

Where $\mathrm{n}$ is the number of days $4^{\text {th }}, 8^{\text {th }}, 12^{\text {th }}, 16^{\text {th }}$.

\section{Incision Model}

In this study, before to skin excision, Skin surface was clearly shaved. Incision wounds of about $6 \mathrm{~cm}$ in length and $2 \mathrm{~mm}$ in depth were made with a sterile scalpel under anesthetized by administering pentobarbitone sodium ( $25 \mathrm{mg} / \mathrm{kg}$ of b.w i.p). The skin was held together by stitching it at $0.5 \mathrm{~cm}$ intervals with black silk. Stitching was done with surgical thread (no. 000) and a curved needle (no. 9). The continuous thread on both wound edges was tightened to ensure proper wound closure. When the wounds had healed properly Sutures have been cut on eighth post-wounding day, and the tensile strength of the skin, identified as the weight in gram needed to break open the injury, calculated with a tensiometer on the tenth day. ${ }^{21}$

Tensile strength was measured using the formula:

Tensile strength $=\frac{\text { Breaking strength }(\mathrm{g})}{\text { The cross-sectinoal area of } \operatorname{skin}\left(\mathrm{mm}^{2}\right)}$

\section{Statistical analysis}

All data was expressed by mean \pm SD with $n=6$ group. Statistical significance was determined with the help of one way analysis of variance (ANOVA) followed 
by Dennett's test. When $P<0.05$ compared to Positive control, the data is considered significant.

\section{RESULTS}

\section{Qualitative phytochemical analysis in almond (extract)}

Qualitative phytochemical study of ethanolic extract of Prunus amygdalus demonstrated the presence of Alkaloid, Tannin, Flavonoid, Phenols, Terpenoids, saponins. The Qualitative phytochemical studies of ethanolic nut extract of Prunus amygdalus Batsch revealed in Table 1.

In ointment formulations, there was no noticeable difference in parameters like color, odor, Consistency, spreadability study and during the course of the analysis, no phase separation was observed. In skin irritant examination, no stains on rat skin were found.

\section{Wound healing activity of F1-PAO and F2-PAE ointments}

When compared to the Positive control groups, there was a significant enhanced in the percentage of wound closure; thus, complete wound healing occurred faster in the test groups. The wound area decreased from day to day (Table 2) in all five groups in the excision wound model, but there was a major decline $(P<0.05)$ in wound area treated with Betadine and F1-PAO AND F2-PAE ointment formulation (Figure 1 display the graphs of excision model).

The study on excision wound model showed the treatment on $12^{\text {th }}$ day, Control group reveals $80.70 \%$, Negative control shows $85.5 \%$, and where as positive control / standard groups (Betadine) treated rats showed 100\% healing. On the other hand, F1-PAO and F2-PAE ointment formulations treated rats showed the $91.03 \%$ and $92.20 \%$ of healing process. In the incision wound model significantly enhanced the tensile strength (Table 3 and Figure 2 graphs of incision model), Positive control treated with betadine showed $715 \mathrm{~g} / \mathrm{mm}^{2}$, test

Table 1: Qualitative phytochemical screening of ethanolic seed extracts of Prunus amygdalus Batsch.

\begin{tabular}{|c|c|c|c|}
\hline S.No. & Phytochemicals & Test & Results \\
\hline 1 & Saponins & Froth test & + ve \\
\hline 2 & Triterpenoids & Salkowski test & + ve \\
\hline 3 & Tannins & Gelatin test & $+v e$ \\
\hline 4 & Alkaloids & $\begin{array}{c}\text { Mayer's test } \\
\text { Dragendroff's test }\end{array}$ & $\begin{array}{c}+v e \\
+v e\end{array}$ \\
\hline 5 & Phenols & Ferric chloride test & $+v e$ \\
\hline 6 & Flavonoids & Alkaline reagent test & $+v e$ \\
\hline 7 & Steroids & Liebermann-Buchard test & $-v e$ \\
\hline
\end{tabular}

$+\mathrm{ve}=$ Present, $-\mathrm{ve}=$ Absent
Table 2: Wound healing activity of F1-PAO and F2-PAE in Excision wound Model.

\begin{tabular}{|c|c|c|c|c|}
\hline \multirow{3}{*}{ Group } & \multicolumn{4}{|c|}{ Wound area $\left(\mathrm{mm}^{2}\right) \pm$ S.D and Degree of } \\
& \multicolumn{4}{|c|}{ Pound contraction (\%)* } \\
& $4^{\text {th }}$ & $\mathbf{8}^{\text {th }}$ & $\mathbf{1 2}^{\text {th }}$ & $\mathbf{1 6}^{\text {th }}$ \\
\hline \multirow{2}{*}{ Control } & $15.89 \pm$ & $8.03 \pm$ & $3.79 \pm$ & $0.785 \pm$ \\
& 0.63 & 1.05 & 0.79 & 0.62 \\
& $19.90^{*}$ & $59.11^{*}$ & $80.70^{*}$ & $96.0^{*}$ \\
\hline Negative & $14.85 \pm$ & $7.063 \pm$ & $2.83 \pm$ & $0.196 \pm$ \\
Control & 0.59 & 0.75 & 1.03 & 0.46 \\
& $29.38^{*}$ & $64.03^{*}$ & $85.5^{*}$ & $99.0^{*}$ \\
\hline Positive & $11.93 \pm$ & $4.90 \pm$ & $0.00 \pm$ & $0.00 \pm$ \\
Control & 0.93 & 1.009 & 0.00 & 0.00 \\
& $39.25^{*}$ & $75.05^{*}$ & $100.0^{*}$ & $100.0^{*}$ \\
\hline F1-PAO & $12.87 \pm$ & $6.60 \pm$ & $1.76 \pm$ & $0.00 \pm$ \\
& 0.78 & 0.60 & 0.51 & 0.00 \\
& $34.47^{*}$ & $66.39^{*}$ & $91.03^{*}$ & $100.0^{*}$ \\
\hline F2-PAE & $12.56 \pm$ & $6.15 \pm$ & $1.56 \pm$ & $0.00 \pm$ \\
& 0.59 & 0.65 & 0.62 & 0.00 \\
& $36.04^{*}$ & $68.68^{*}$ & $92.20^{*}$ & $100.0^{*}$ \\
\hline
\end{tabular}

All value are expressed in mean $\pm S D$, $(N=6$, represent number of animal in each group) *

Represent statistically significant $p<0.01$, Represent statistical significant value $<0.05$ which are calculated with the help of one way analysis of variance (one way ANOVA). The comparison with Positive control groups

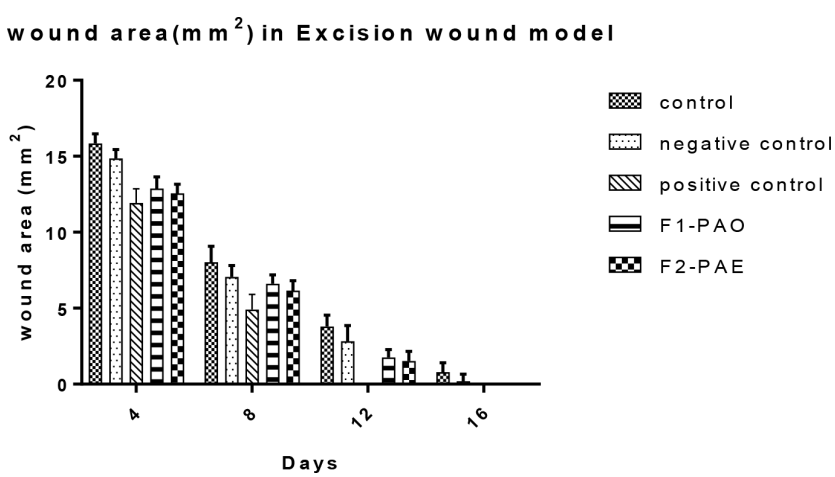

Figure 1: Wound area of F1-PAO and F2-PAE formulation in Excision model.

groups treated with F1-PAO and F2-PAE showed $575 \mathrm{~g} / \mathrm{mm}^{2}$ and $675 \mathrm{~g} / \mathrm{mm}^{2}$. Figure 3 describe the wound healing activity of F1-PAO and F2-PAE in Excision wound model

\section{DISCUSSION}

The current study aimed to examine the wound healing efficacy of ethanolic and n-haxane extract ointment formulations utilising in-vivo wound healing models. Belachew et al. perform similar activity on ointment formulation of Hagenia abyssinica leave extract 5\% and $10 \%$, their study was found the percentage of wound contraction is $98.67 \%$ and $100 \%$. In our study, ointment formulation also showed that percentage 
Table 3: Wound healing activity of F1-PAO and F2-PAE Tensile strength $\left(\mathrm{g} / \mathrm{mm}^{2}\right)$ in Incision wound model.

\begin{tabular}{|c|c|}
\hline Group & Tensile streagth $\left(\mathbf{g} / \mathbf{m m}^{2}\right)$ \\
\hline Control & $210 \pm 4.38$ \\
\hline Negative control & $398 \pm 5.20$ \\
\hline Positive control & $715 \pm 4.60$ \\
\hline F1-PAO & $575 \pm 5.93$ \\
\hline F2-PAE & $675 \pm 3.90$ \\
\hline
\end{tabular}

All value are expressed in mean $\pm S D,(N=6$, represent number of animal in each group) *

Represent statistically significant $p<0.01$, Represent statistical significant value $<0.05$ which are calculated with the help of one way analysis of variance (one way ANOVA). The comparison with Positive control groups

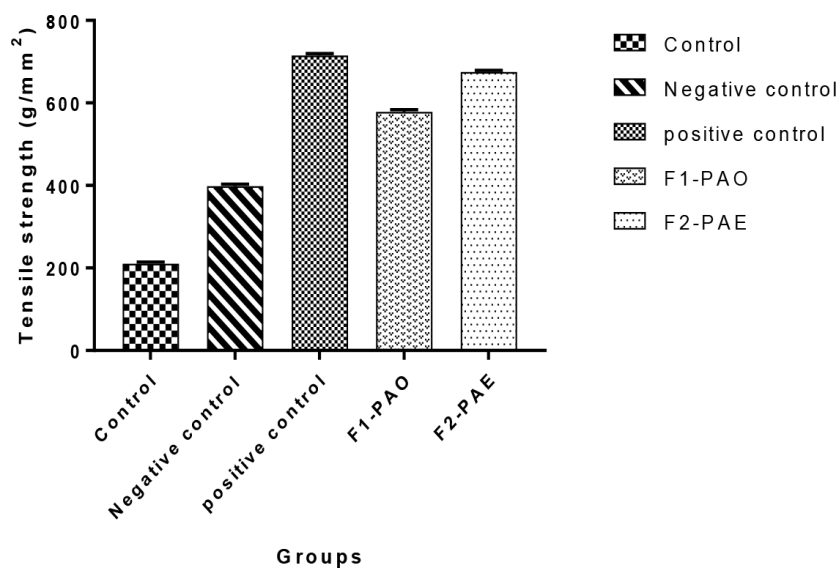

Figure 2: Tensile strength of F1-PAO and F2-PAE in incision model.

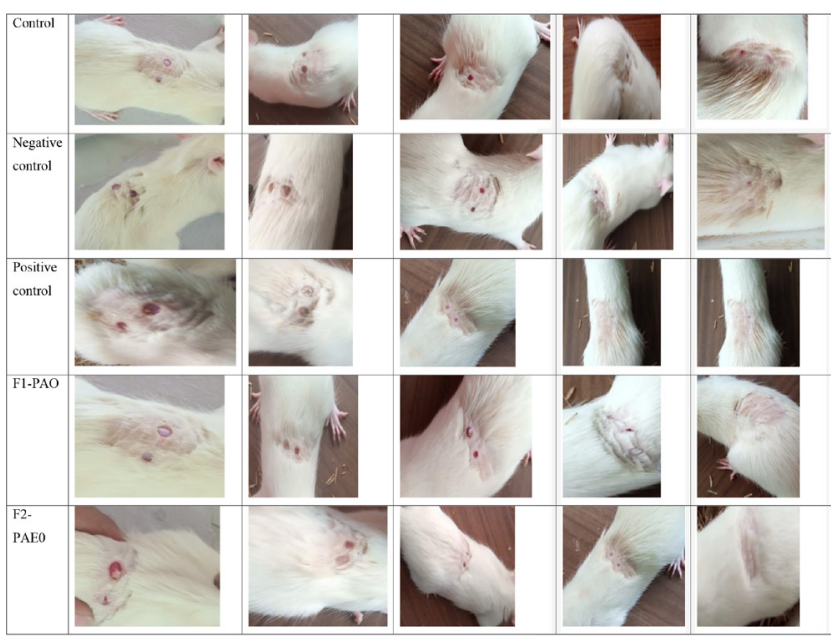

Figure 3: Wound healing activity of F1-PAO and F2-PAE in Excision wound model.

of wound contraction is $91.03 \%$ and $92.20 \%$ which is comparatively showed that our formulation is also having strong wound healing potential compared with the previously reported study. ${ }^{22}$
According to the report attained in the present study, it is possible to assume that the ointment of Prunus amygdalus nut extract has considerable wound healing activity. The above results indicate that the wound healing properties of the Prunus amygdalus nut were comparable with the control indicated in standard literature. Wound-healing potential occurs to be due to the influence of its active principles, which speed up the healing process and give the healed wound breaking strength. Further, Wound healing process of ointment formulations treated with F1-PAE was found to be better than F1-PAO.

The investigation shows that both ointment formulation i.e F1-PAO and F2-PAE treated groups have good wound healing activities which can be due to the phytochemicals like tannins, saponins, alkaloids and triterpenoids. Further studies are important to identify the bioactive component present in the extract used in these researches.

\section{CONCLUSION}

This study suggested the wound healing activity of Prunus amygdalus (Batsch.) nut ethanolic extract and n-hexane oil extract was found to be significant when compared with standard. Wound contraction and the tensile strength found enough to support further evaluation. Yet the many of things are still in pipeline to investigate such as the exact phytoconstituents responsible for this activity and the possible mechanism behind the action and that will be the future prospects of our study.

\section{ACKNOWLEDGEMENT}

The authors are thankful to the Anand College of pharmacy for provided necessary infrastructure and financial support for this work.

\section{REFERENCES}

1. Singer AJ, Clark RAF. Cutaneous wound healing. N Engl J Med. 1999;341(10):738-46. doi: 10.1056/NEJM199909023411006.

2. Ibrahim N', Wong SK, Mohamed IN, Mohamed N, Chin KY, Ima-Nirwana S, et al. Wound healing properties of selected natural products. Int J Environ Res Public Health. 2018;15(11):2360. doi: 10.3390/ijerph15112360, PMID 30366427.

3. Singh S, Jangde R, Daharwal SJ. An updated review on herbal drug in wound healing. Res J Pharm Technol. 2019;12(6):3089-97. doi: 10.5958/0974360X.2019.00523.7.

4. Samal S, Rath B, Pradhan S, Pattnaik S. Wound healing activity of topical formulation of Lantana camara Linn flower water distillate in Wistar rats. Indian J Pharm Pharmacol. 2017;4(1):29-33.

5. Rajput RT, Gohil KJ. Development and evaluation of herbomineral ointment from Bauhinia variegata L. for wound healing effects. Indian J Nat Prod Resour. 2020 Jun;11(2):96-100.

6. Kirtikar KR, Basu BD, An ICS. Indian medicinal plants, Volume-II. Vol. 1988. Dehradun: International Book Distributers. p. 951-4. 
7. Chopra et al. Glossary of Indian medicinal plants. New Delhi: Council of Scientific and Industrial Research; 1956;204.

8. Esfahlan AJ, Jamei R, Esfahlan RJ. The importance of almond (Prunus amygdalus L.) and its by-products. Food Chem. 2010 May 15;120(2):349-60. doi: 10.1016/j.foodchem.2009.09.063.

9. Samuel DS, Geetha RV. Antioxidant activity of dry fruits: A short review. Res J Pharm Technol. 2014 Nov 1;7(11):10.

10. Anwar M, Shousha WG, El-mezayen HA, El-Wassef M, Nazif NM, El-bana MA. Antiatherogenic effect of almond oil in streptozotocin induced diabetic rats. Journal of Applied Pharmaceutical Science. 2013;3(10):59.

11. Nayak BS, Sandiford S, Maxwell A. Evaluation of the wound-healing activity of ethanolic extract of Morinda citrifolia L. leaf. Evid Based Complement Alternat Med. 2009 Sep 1;6(3):351-6. doi: 10.1093/ecam/nem127, PMID 18955257.

12. Akubude VC, Maduako J, Egwuonwu C, Ajala EO, Olaniyan AM, Ozumba IC, et al. Almond oil: Powerhouse of nutrients. Agric Eng Int CIGR J. 2020 Oct 12;22(3):190-201.

13. Akubude VC, Maduako J, Egwuonwu C, Ajala EO, Olaniyan AM, Ozumba IC, et al. Almond oil: Powerhouse of nutrients. Agric Eng Int CIGR J. 2020 Oct 12;22(3):190-201.

14. Shah KH, Patel JB, Shrma VJ, Shrma RM, Patel RP, Chaunhan UM. Evaluation of antidiabetic activity of Prunus amygdalus Batsch in streptozotocin induced diabetic mice. Res J Pharm Biol Chem Sci. 2011 Apr-Jun;2(2):432-4.
15. Anwar M, Shousha WG, El-mezayen HA, El-Wassef M, Nazif NM, El-bana MA. Antiatherogenic effect of almond oil in streptozotocin induced diabetic rats. Journal of Applied Pharmaceutical Science. 2013 Oct 1;3(10):59.

16. Evans WC. Trease and evans' pharmacognosy. 16th ed. London: Sauders Elsevier; 2009

17. Nayak BS, Pinto Pereira LM. Catharanthus roseus flower extract has woundhealing activity in Sprague Dawley rats. BMC Complement Altern Med. 2006;6(1):41. doi: 10.1186/1472-6882-6-41, PMID 17184528.

18. Sawant SE, Tajane MD. Formulation and evaluation of herbal ointment containing Neem and Turmeric extract. J Sci Innov Res. 2016;5(4):149-51.

19. R. S, C. R. B, G. J, Menon AS, K. A, G. B. Formulation, Evaluation and HPTLC Analysis of Topical Ointment Containing Calendula officinalis and Echinacae purpurae Mother Tinctures. IJRASB. 2020 Nov 13;7(6):78-84. doi: 10.31033/ijrasb.7.6.13

20. Kokane DD, More RY, Kale MB, Nehete MN, Mehendale PC, Gadgoli CH. Evaluation of wound healing activity of root of Mimosa pudica. J Ethnopharmacol. 2009 Jul 15;124(2):311-5. doi: 10.1016/j.jep.2009.04.038, PMID 19397984.

21. Saha K., Mukherjee P.K., Das J., Pal, M. Saha B.P. Wound healing activity of Leucas lavandulaefolia Rees. J. Ethnopharmacol. 1997; 56: 139-144.

22. Belachew TF, Asrade S, Geta M, Fentahun E. In vivo evaluation of wound healing and anti-inflammatory activity of $80 \%$ methanol crude flower extract of Hagenia abyssinica (Bruce) JF Gmel in mice. Evid Based Complement Alternat Med. 2020;2020:1-12. doi: 10.1155/2020/9645792.

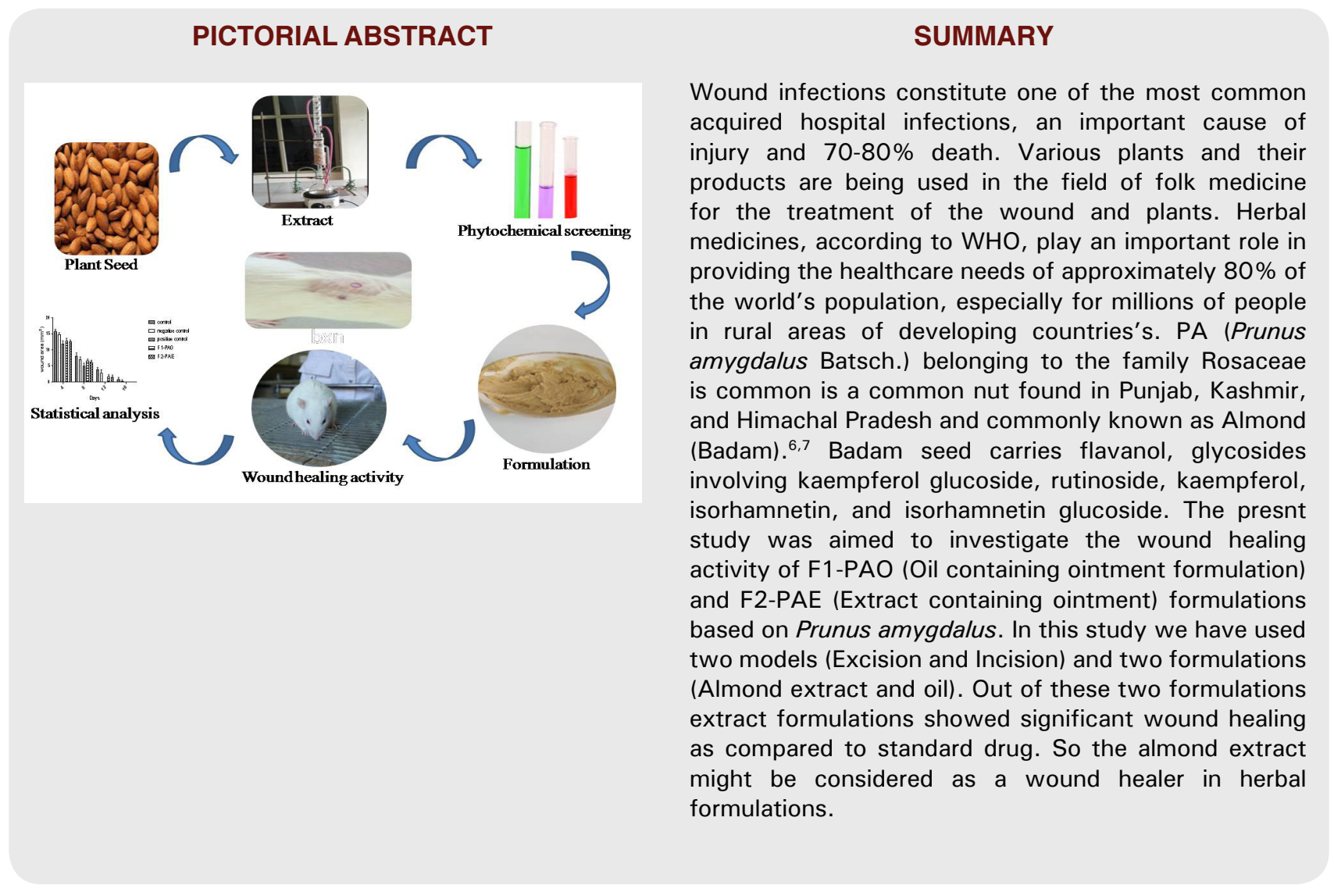




\section{About Authors}

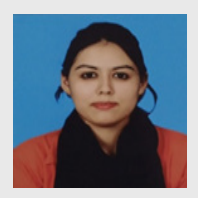

Ms. Diksha Singh, presently working as PG scholar, Department of Pharmacology at Anand College of Pharmacy, Agra. Author's areas of interest is research activities in conventional medicine system, standardization.

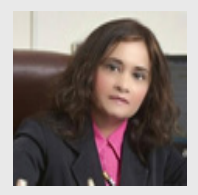

Prof. (Dr.) Kashmira J. Gohil, presently working as Dean, at Anand College of Pharmacy, Agra. Authors areas of interest is research activities in conventional, novel drug delivery system and herbomineral formulations.

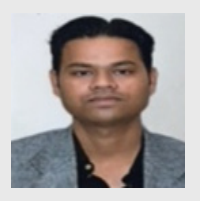

Mr. Vikash Sharma, presently working as Assistant Professor at Department of Pharmacology at Anand College of Pharmacy, Agra. Author's areas of interest are research activities in conventional drug standardization and chemical fingerprinting analysis.

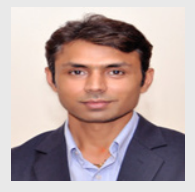

Prof. Shiv Shankar Shukla, Presently working as Professor, Columbia Institute of Pharmacy, Raipur (C.G.). Author's areas of interest are research activities in conventional drug standardization and chemical fingerprinting analysis.

Cite this article: Singh D, Gohil KJ, Sharma V. In vivo wound Healing Activity of Ointment based Formulation for Prunus amygdalus (Batsch.) on Rats. Indian J of Pharmaceutical Education and Research. 2022;56(1):184-90. 